\title{
Effects of fish oil and conjugated linoleic acids on expression of target genes of PPAR $\alpha$ and sterol regulatory element-binding proteins in the liver of laying hens
}

\author{
Bettina König, Julia Spielmann, Kati Haase, Corinna Brandsch, Holger Kluge, Gabriele I. Stangl \\ and Klaus Eder* \\ Institute of Agricultural and Nutritional Sciences, Martin-Luther-University of Halle-Wittenberg, Emil-Abderhalden-Strasse 26, \\ Halle (Saale) D-06108, Germany
}

(Received 2 March 2007 - Revised 31 October 2007 - Accepted 31 October 2007 - First published online 21 January 2008)

In mammals, (n-3) PUFA and conjugated linoleic acids (CLA) act as activators of PPAR $\alpha$ and alter nuclear concentrations of sterol regulatory element-binding proteins (SREBP) in the liver, and thereby influence hepatic lipid catabolism and synthesis. In this study, we investigated the hypothesis that (n-3) PUFA and CLA exert similar effects in the liver of laying hens. Thirty hens (64 weeks old) were fed diets containing $30 \mathrm{~g} / \mathrm{kg}$ of sunflower oil (control), fish oil (salmon oil) or CLA in TAG form (containing predominantly cis-9, trans-11 CLA and trans-10, cis-12 CLA) for 5 weeks. Hens fed fish oil had a higher expression of some PPAR $\alpha$ target genes and a lower nuclear concentration of SREBP-2 in the liver and lower concentrations of cholesterol and TAG in plasma than control hens. Nuclear concentration of SREBP-1 and its target genes involved in lipogenesis were not altered in hens fed fish oil. Hens fed CLA had increased concentrations of TAG and cholesterol in the liver. However, their mRNA levels of PPAR $\alpha$ target genes and nuclear concentrations of SREBP-1 and SREBP-2 as well as mRNA levels of their target genes in the liver were largely unchanged compared to control hens. The results of this study suggest that (n-3) PUFA cause a moderate activation of PPAR $\alpha$ and lower cholesterol synthesis but do not impair fatty acid synthesis in the liver of laying hens. CLA lead to an accumulation of TAG and cholesterol in the liver of hens by mechanisms to be elucidated in further studies.

Laying hens: PPAR $\alpha$ : Sterol regulatory element-binding proteins: Fish oil: Conjugated linoleic acid

In laying hens, hepatic lipid metabolism plays an important role for the production of eggs. Compared with mammals, laying hens have a very high rate of hepatic synthesis of TAG, phospholipids and cholesterol, which plays a crucial role in lipid deposition in egg yolk $^{(1)}$. Lipids synthesised in the liver are incorporated into TAG-rich lipoproteins that are secreted into the blood. Plasma of laying hens therefore contains extremely high concentrations of TAG, most of which are localised in VLDL ${ }^{(2)}$. VLDL with a particle diameter of 25 to $44 \mathrm{~nm}$ are bound to specific oocyte receptors and are deposited in developing egg yolk follicles ${ }^{(1)}$. An impairment of hepatic lipid synthesis leads to a stop of egg production $^{(3)}$.

Hepatic lipid metabolism is regulated by transcription factors such as PPAR $\alpha$ and sterol regulatory element-binding proteins (SREBP). PPAR $\alpha$ is a member of the nuclear receptor superfamily. In mammals, it is highly expressed in tissues with high fatty acid oxidation such as liver or muscle ${ }^{(4)}$. PPAR $\alpha$ regulates the expression of target genes by binding to DNA sequence elements as heterodimers with the 9-cis retinoic acid receptor after activation. PPAR $\alpha$ target genes in rodents and human subjects are mainly involved in cellular fatty acid uptake and intracellular fatty acid transport, mitochondrial and peroxisomal fatty acid oxidation, ketogenesis and gluconeogenesis ${ }^{(5)}$. PPAR $\alpha$ is activated by lipid soluble compounds such as eicosanoids, fatty acids or fibrates ${ }^{(4)}$. In mammals, PPAR $\alpha$ activation leads to a strong reduction of plasma and liver TAG concentration due to an enhanced $\beta$-oxidation of fatty acids, an inhibition of TAG synthesis and an increased activity of lipoprotein lipase ${ }^{(6)}$.

SREBP are transcription factors which have been identified and recognised as key regulators of lipid synthesis and homeostasis. SREBP-1c preferentially activates genes required for fatty acid synthesis while SREBP-2 preferentially activates the LDL receptor gene and various genes required for cholesterol synthesis such as 3-hydroxy-3-methylglutaryl-CoA (HMG-CoA) reductase ${ }^{(7)}$. SREBP are synthesised as inactive integral endoplasmic reticulum membrane proteins and are activated by proteolytic cleavages in the Golgi releasing the mature N-terminal domain of SREBP that then translocates to the nucleus and activates transcription of sterol regulatory element-containing genes ${ }^{(7-9)}$. 
Recently, it has been shown that both PPAR $\alpha$ and SREBP are expressed in chicken liver and that they have a high homology with mouse, rat and human PPAR $\alpha$ and SREBP, respectively ${ }^{(10-13)}$. We have recently shown that feeding laying hens clofibrate, a synthetic PPAR $\alpha$ agonist, causes up-regulation of several genes recognised as typical PPAR $\alpha$ target genes in rodents and human subjects which in turn led to dramatically reduced concentrations of TAG in liver and plasma of the hens ${ }^{(3)}$. Moreover, it has also been shown that SREBP-1 is the major regulator of lipogenesis and that SREBP-2 controls the cholesterol biosynthetic pathway in chick liver as in mammals ${ }^{(14)}$.

In mammals, both SREBP and PPAR $\alpha$ are also activated by various naturally occurring lipids such as $n-3$ fatty acids or conjugated linoleic acids (CLA) $)^{(15-17)}$. Long-chain $n-3$ PUFA activate PPAR $\alpha$, which stimulates mitochondrial and peroxisomal $\beta$-oxidation of fatty acids, and reduces the transcription of SREBP-1, which leads to an inhibition of de novo fatty acid synthesis due to a down-regulation of lipogenic enzymes ${ }^{(18-20)}$. These events are involved in the hypotriacylglycerolaemic effects of $n-3$ PUFA in mammals. CLA have also be shown to be activators of PPAR $\alpha^{(15,16,21)}$; in contrast to $n-3$ PUFA, CLA however do not reduce but rather increase transcription of SREBP-1 and SREBP-2 in mammalian liver cells which leads to an increased de novo synthesis of fatty acids and cholesterol in the liver ${ }^{(22,23)}$. Whether $n-3$ PUFA or CLA are able to activate PPAR $\alpha$ also in laying hens or to influence the action of SREBP, and thereby influence the lipid metabolism of laying hens, has not yet been investigated. Therefore, we performed an experiment in which hens were fed diets with fish oil or a CLA oil in comparison to sunflower oil which was used as a reference. To study the PPAR $\alpha$-activating effect of these oils, we determined mRNA levels of various genes which were shown to be up-regulated by PPAR $\alpha$ activation in rat models. These included carnitine palmitoyltransferase (CPT)-1A, acyl-CoA oxidase (ACO) and the peroxisomal bifunctional enzyme (enoyl-CoA hydratase/L-3-hydroxyacyl-CoA dehydrogenase), all genes involved in mitochondrial or peroxisomal $\beta$-oxidation $^{(5)}$. To assess whether fish oil or CLA influence gene expression or proteolytic activation of SREBP, we determined mRNA levels and nuclear concentrations of SREBP-1c and SREBP-2. Moreover, we determined gene expression of insulin-induced genes (Insig), proteins that are involved in the proteolytic activation of $\operatorname{SREBP}^{(24,25)}$ and the important SREBP target genes involved in fatty acid synthesis (acetylCoA carboxylase (ACC), fatty acid synthase (FAS)) and cholesterol uptake (LDL receptor) and synthesis (HMG-CoA reductase). To study whether potential effects on PPAR $\alpha$ or SREBP lead to phenotypic alterations in the lipid metabolism, we also determined concentrations of TAG and cholesterol in liver, plasma and egg yolk.

\section{Materials and methods}

\section{Animals and treatment}

An experiment was conducted with thirty Lohmann White layers (64 weeks old) with an average body weight of 1732 (SD 136) g. The hens were allotted to three groups of ten each. They received a nutritionally adequate diet which was supplemented with $(30 \mathrm{~g} / \mathrm{kg}$ ) sunflower oil (from a local supermarket; control group), salmon oil (Caesar \& Loretz $\mathrm{GmbH}$, Hilden, Germany) or CLA oil (BASF, Ludwigshafen, Germany) (Table 1). The CLA oil contained $60 \mathrm{~g}$ CLA isomers per $100 \mathrm{~g}$ CLA oil in TAG form with cis-9, trans-11 and trans-10, cis-12 as the main isomers. The fatty acid composition of total lipids of the three experimental diets is given in Table 1.

The basal diet contained ( $\mathrm{g} / \mathrm{kg}$ diet): 465 wheat, 130 extracted soya bean meal, 120 corn, 80 peas, $75 \mathrm{CaCO}_{3}, 70$ extracted sunflower meal, 30 oil, $12.5 \mathrm{Ca}_{2} \mathrm{PO}_{4}, 10$ vitamin and mineral premix, 5 fibre, $2 \mathrm{NaCl}$ and 0.5 DL-methionine. This diet contained $11.4 \mathrm{MJ}$ metabolisable energy $/ \mathrm{kg}$ and $169 \mathrm{~g}$ crude protein $/ \mathrm{kg}$ (as determined by the official German VDLUFA methods) ${ }^{(26)}$. Concentrations of essential amino acids, minerals and vitamins were in accordance with recommendations of the German Nutrition Society ${ }^{(27)}$ for laying hens. The amount of vitamin $\mathrm{E}$ supplied by the premix was $40 \mathrm{mg} / \mathrm{kg}$ (as all-rac- $\alpha$-tocopheryl acetate).

The hens were kept one bird per cage in an environmentally controlled room at $18^{\circ} \mathrm{C}$. The room was lit for $14 \mathrm{~h}$ daily. Feed (mash) and water (via nipple drinkers) were available ad libitum. The experiment was conducted over a 5-week period. All procedures followed established guidelines for the care and handling of animals and were approved by the veterinary council of Saxony-Anhalt. Body weight at the start and end of the experiment, total egg production and weekly feed consumption were monitored.

\section{Sample collection}

After the end of week 5, overnight-fasted hens were anaesthetised by a strike on the head and were then decapitated. Blood was collected in heparinised tubes; plasma was separated by centrifugation at $1500 \mathrm{~g}$ for $10 \mathrm{~min}$ at $4^{\circ} \mathrm{C}$. Liver was excised, weighed and immediately snap frozen in liquid $\mathrm{N}_{2}$. Aliquots of

Table 1. Fatty acid composition of total lipids ( $\mathrm{g} / 100 \mathrm{~g}$ total fatty acids) of the experimental diets

\begin{tabular}{|c|c|c|c|}
\hline Fatty acid & Control diet & Salmon oil diet & CLA oil diet \\
\hline C14:0 & 0.11 & $4 \cdot 26$ & $0 \cdot 14$ \\
\hline C16:0 & $9 \cdot 27$ & $15 \cdot 85$ & $9 \cdot 40$ \\
\hline C16: 1 & 0.15 & $4 \cdot 87$ & 0.21 \\
\hline C18:0 & $3 \cdot 11$ & $3 \cdot 18$ & $3 \cdot 16$ \\
\hline C18: 1 cis-9 + cis-11 & $27 \cdot 97$ & $19 \cdot 09$ & 23.06 \\
\hline C18: $2(n-6)$ & $55 \cdot 10$ & $22 \cdot 25$ & $22 \cdot 04$ \\
\hline C18: 2 cis-9, trans-11 & $-^{\star}$ & - & $18 \cdot 47$ \\
\hline C18: 2 trans-10, cis-12 & - & - & $18 \cdot 69$ \\
\hline C18: 2 cis-10, cis-12 & - & - & 1.03 \\
\hline C18: 2 trans- 9, trans-11 & - & - & 0.23 \\
\hline C18: $3(n-3)$ & 1.46 & 1.58 & 1.48 \\
\hline C18: $4(n-3)$ & - & 1.49 & - \\
\hline C20: 0 & 0.29 & 0.45 & 0.38 \\
\hline $\mathrm{C} 20: 1(n-11)$ & 0.40 & $3 \cdot 19$ & - \\
\hline $\mathrm{C} 20: 4(n-3)$ & - & $0 \cdot 81$ & - \\
\hline $\mathrm{C} 20: 5(n-3)$ & - & 8.07 & - \\
\hline C22: 0 & 0.56 & $0 \cdot 19$ & 0.46 \\
\hline $\mathrm{C} 22: 1(n-9)$ & - & 3.59 & - \\
\hline $\mathrm{C} 22: 5(n-3)$ & - & 1.67 & - \\
\hline C22: $6(n-3)$ & - & $8 \cdot 19$ & - \\
\hline
\end{tabular}

CLA, conjugated linoleic acids.

* $<0.1 \mathrm{~g} / 100 \mathrm{~g}$ total fatty acids. 
liver for RNA isolation were stored at $-80^{\circ} \mathrm{C}$; other samples were stored at $-20^{\circ} \mathrm{C}$. To determine egg yolk weight and concentrations of yolk lipids and fatty acid composition, two eggs from each hen were sampled at the end of week 5. Eggs were cooked in water for $10 \mathrm{~min}$. The two eggs from each hen were pooled for determination of TAG and cholesterol concentrations in egg yolk.

\section{Analysis of TAG, cholesterol and fatty acids}

Lipids from liver and cooked egg yolks were extracted with a mixture of $n$-hexane and isopropanol $(3: 2, v / v)^{(28)}$. For determination of the concentrations of TAG and cholesterol in the liver and egg yolks, aliquots of the lipid extracts were dried and the lipids were dissolved using Triton $\mathrm{X}-100^{(29)}$. Concentrations of TAG and cholesterol in plasma, liver and egg yolks were determined using enzymatic reagent kits (VWR International, Darmstadt, Germany, catalogue no. 1.14830, 1.14856). The fatty acid composition of dietary oils was determined by gas chromatography of fatty acid methyl esters which were prepared by methylation with trimethylsulfonium hydroxide ${ }^{(30)}$. Concentrations of CLA isomers in the CLA oil were analysed by $\mathrm{Ag}^{+}-\mathrm{HPLC}-\mathrm{DAD}{ }^{(31)}$.

\section{$R T-P C R$ analysis}

Total RNA was isolated from livers by TRIZOL reagent (Sigma-Aldrich, Steinheim, Germany) according to the manufacturer's protocol. cDNA synthesis was carried out as described $^{(32)}$. The mRNA level of genes was measured by realtime detection PCR using SYBR ${ }^{\circledR}$ Green I and the Rotor Gene 2000 system (Corbett Research, Mortlake, Australia). PCR was performed with $1.25 \mathrm{U}$ Taq DNA polymerase (Promega, Mannheim, Germany), $500 \mu \mathrm{M}$ desoxyribonucleoside triphosphates and $26.7 \mathrm{pmol}$ of the specific primers (Operon Biotechnologies, Cologne, Germany; Table 2). For determination of mRNA level a threshold cycle $\left(\mathrm{C}_{\mathrm{t}}\right)$ and amplification efficiency was obtained from each amplification curve using the software RotorGene 4.6 (Corbett Research, Australia). Calculation of the relative mRNA level was made using the amplification efficiencies and the $C_{t}$ values ${ }^{(33)}$. The housekeeping gene $\beta$-actin was used for normalisation.

\section{Immunoblot analysis}

Nuclear extracts of livers were prepared from fresh tissue samples ${ }^{(34)}$. The protein content of the samples was determined by the bicinchoninic acid assay. Bicinchoninic acid reagent was purchased from Interchim (Montfucon, France). Equal amounts of proteins were pooled from five hens per group and $90 \mu \mathrm{g}$ protein per lane were separated on $10 \%$ SDS-polyacrylamide gels and electrotransferred to a nitrocellulose membrane (Pall, Pensacola, FL, USA). Polyclonal anti-SREBP-1 antibody (Santa Cruz Biotechnology, Inc., Heidelberg, Germany) and polyclonal anti-SREBP-2 antibody (Abcam plc, Cambridge, UK) were used to detect nuclear SREBP-1 and nuclear SREBP-2, respectively, using enhanced chemiluminescence reagent (GE Healthcare, Munich, Germany) and a chemiluminescence imager (biostep $\mathrm{GmbH}$, Jahnsdorf, Germany). Signals were analysed with the Phoretix TotalLab TL100 software. The anti-rabbit-IgG peroxidase conjugate antibody was purchased from Sigma-Aldrich (Steinheim, Germany).

\section{Statistical evaluation}

Treatment effects were evaluated by one-factorial ANOVA. For significant $F$ values $(P<0.05)$, means of the treatments (fish oil, CLA) were compared pairwise with the control group by Student's $t$ test. Means were considered significantly different for $P<0 \cdot 05$. Values are given as means with their standard deviation.

\section{Results}

Body and liver weights, feed intake and egg production

Initial body weights of the hens did not differ between the three groups (control, 1747 (SD 146) g; fish oil, 1723 (SD 175) g; CLA, 1719 (SD 95) g, $n 10$ for each group). Liver weights of hens fed diets containing either fish oil or CLA did not differ from those of control hens (control, 44.0 (SD 8.8) g; fish oil, 40.6 (SD 4.6) g; CLA, 48.6 (SD 5.9) g). However, liver weights of hens fed the diet containing CLA were higher than those of hens fed the diet containing fish oil $(P<0 \cdot 05)$. Feed intake of the hens during the experimental period (control, 4059 (SD 372) g; fish oil, 4121 (SD 273) g;

Table 2. Characteristics of the specific primers used for RT-PCR analysis

\begin{tabular}{|c|c|c|c|c|c|}
\hline Gene & Forward primer (from $5^{\prime}$ to $3^{\prime}$ ) & Reverse primer (from $5^{\prime}$ to $3^{\prime}$ ) & $\mathrm{bp}$ & Annealing temperature $\left({ }^{\circ} \mathrm{C}\right)$ & NCBI GenBank \\
\hline $\mathrm{ACO}$ & ACGCCCAAATTACTCAGGTG & GGATTTCTTTGCCCACTCAA & 173 & 60 & NM_001006205 \\
\hline $\mathrm{ACC}$ & TGTGGCTGATGTGAGCTTTC & ACTGTCGGGTCACCTTCAAC & 152 & 60 & NM_205505 \\
\hline$\beta$-Actin & ATGAAGCCCAGAGCAAAAGA & GGGGTGTTGAAGGTCTCAAA & 223 & 62 & L08165 \\
\hline Bifunctional enzyme & ATTCTTGCAGTCTGGCACCT & CCTGTGGTCATAGCCTGGTT & 255 & 62 & BG713425 \\
\hline CPT-1A & GATTTGGACCTGTGGCTGAT & CTGCTTTCATTCGCTGTTCA & 262 & 62 & NM_001012898 \\
\hline FAS & GCTGAGAGCTCCCTAGCAGA & TCCTCTGCTGTCCCAGTCTT & 164 & 60 & NM_205155 \\
\hline HMG-CoA-R & TCCСТGAАСССТСАТСТTTG & TCTGCAAGAATACGGCTCCT & 250 & 60 & NM_204485 \\
\hline Insig-1 & CGACCCATCCAAGAAGATGT & GCATTTGAGGAAGGATGGAA & 212 & 60 & NM_001030966 \\
\hline Insig-2 & GCTCGGATACGGATTTGTGT & TTGAACTCCTTCAGGGATGG & 174 & 60 & NM_001031261 \\
\hline LDL receptor & GCAGTCACAGCATCAGCTTC & ACTCGTTGTGTCGCACACTC & 150 & 60 & NM_204452 \\
\hline $\operatorname{PPAR} \alpha$ & AGGCCAAGTTGAAAGCAGAA & GTCTTCTCTGCCATGCACAA & 217 & 60 & NM_001001464 \\
\hline SREBP-1 & GGTGTCAGGGTGCAGTTTTT & TCACTAGAGGTCCCCACGTC & 165 & 60 & AY029224 \\
\hline SREBP-2 & CCAAGGAGAGCCTGTACTGC & CCCATTGAGTCCAGGAAAGA & 217 & 60 & XM_416222 \\
\hline
\end{tabular}

ACO, acyl-CoA oxidase; ACC, acetyl-CoA carboxylase; CPT, carnitine palmitoyltransferase; FAS, fatty acid synthase; HMG-CoA, 3-hydroxy-3-methylglutaryl-CoA; Insig, insulin-induced gene; SREBP, sterol regulatory element-binding protein. 
CLA, 4041 (SD 348) g) and final body weights after 5 weeks (control, 1735 (SD 158) g; fish oil, 1749 (SD 136) g; CLA, 1701 (SD 143) g) did not differ between the three groups. Egg production rate was not different between the three groups of hens (control, 86 (SD 11) \%; fish oil, 86 (SD 10) $\%$; CLA, 87 (SD 9) \%). However, eggs of hens fed the diet containing CLA had heavier yolks than eggs of control hens or hens fed the diet containing fish oil $(P<0.05$; control, 18.2 (SD 1.1) g; fish oil, 17.7 (SD 0.8) g; CLA, 20.9 (SD 1.5) g).

\section{Expression of PPAR $\alpha$ and its target genes in the liver}

Gene expression of PPAR $\alpha$ was detected in the liver of the hens, but PPAR $\alpha$ mRNA level did not differ between the three groups of hens (Fig. 1). Hens fed the diet containing fish oil had significantly higher mRNA levels of ACO $(+45 \%)$ and bifunctional enzyme $(+50 \%)$ in the liver than control hens $(P<0 \cdot 05$, Fig. 1). mRNA level of CPT-1A was not different between hens fed the diet containing fish oil and control hens (Fig. 1). In hens fed the diet containing CLA none of the PPAR $\alpha$ target genes was significantly up-regulated in the liver relative to control hens (Fig. 1). There was however a tendency towards increased mRNA levels of ACO $(+29 \%, P=0 \cdot 10)$ and bifunctional enzyme $(+30 \%, P=0 \cdot 06)$ in hens fed the diet containing CLA compared to control hens. The mRNA level of CPT-1A in the liver was not different between hens fed the diet containing CLA and control hens (Fig. 1).

mRNA levels of Insig, SREBP, concentration of nuclear SREBP and mRNA levels of SREBP target genes in the liver

Hens fed the diet containing fish oil showed a moderately increased level of SREBP-1 mRNA compared to control hens $(+31 \%, P<0.05$; Fig. 2$)$ but concentration of nuclear SREBP-1 protein in the liver was slightly decreased $(-12 \%$, Fig. 3 (A)). Hepatic mRNA levels of the SREBP-1 target genes ACC and FAS were unchanged in

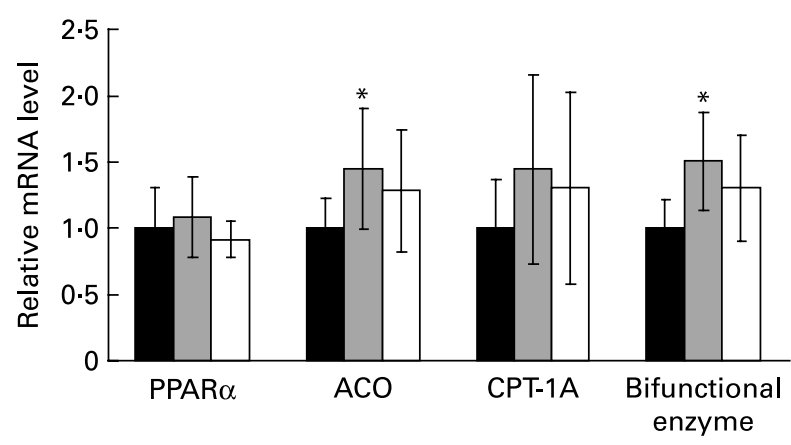

Fig. 1. Effect of feeding laying hens diets containing $(30 \mathrm{~g} / \mathrm{kg})$ sunflower oil (control, $\square$ ), fish oil ( $\square$ ) or conjugated linoleic acids (CLA; $\square$ ) for 5 weeks on the mRNA levels of PPAR $\alpha$, acyl-CoA oxidase (ACO), carnitine palmitoyltransferase (CPT)-1A and bifunctional enzyme in the liver. Total RNA was extracted from the liver and relative mRNA levels of the genes were determined by RT-PCR analysis using $\beta$-actin mRNA level for normalisation. Values are means with standard deviation indicated by vertical bars for ten hens per group. Mean values were significantly different from control group: ${ }^{*} P<0.05$. hens fed the diet containing fish oil compared to control hens (Fig. 2). Hepatic mRNA level of SREBP-2 did not differ between hens fed the diet containing fish oil and those fed the control diet (Fig. 2). The concentration of the nuclear SREBP-2 protein, however, was lower in hens fed the diet containing fish oil than in control hens $(-42 \%$, Fig. 3 (B)). Hepatic mRNA levels of the SREBP-2 target genes Insig-1 $(-36 \%, P<0.05)$ and HMG-CoA reductase $(-24 \%, P<0.05)$ were moderately reduced in hens fed the diet containing fish oil compared to hens fed the control diet; mRNA level of the SREBP-2 target gene LDL receptor, however, did not differ between these two groups of hens (Fig. 2). Hepatic mRNA level of Insig-2 did also not differ between hens treated with fish oil and control hens (Fig. 2).

In hens fed the diet containing CLA, mRNA level of SREBP-1 in the liver was markedly increased in comparison to control hens $(+70 \%, P<0.05$; Fig. 2$)$, while concentration of nuclear SREBP-1 in the liver of hens fed CLA containing diet was only slightly increased $(+23 \%$; Fig. $3(\mathrm{~A}))$. However, mRNA levels of the SREBP-1 target genes ACC and FAS did not differ between these two groups of hens (Fig. 2). Hens fed the diet containing CLA did not differ in hepatic mRNA level of SREBP-2 (Fig. 2) and had slightly reduced concentration of the nuclear SREBP-2 protein $(-17 \%$, Fig. 3 (B)) and a higher mRNA level of the SREBP-2 target gene LDL receptor $(+30 \%, P<0.05$; Fig. 2). mRNA levels of SREBP-2 target genes Insig-1 and HMG-CoA reductase as well as that of Insig-2 did not differ between these two groups of hens (Fig. 2).

Concentrations of TAG and cholesterol in liver, plasma and egg yolk

Hens fed the diet containing fish oil had lower concentrations of TAG and cholesterol in plasma than control hens $(P<0.05$; Table 3). Concentration of TAG and cholesterol in liver did not differ in hens fed fish oil compared to control hens (Table 3). Hens fed the diet containing fish oil moreover tended to have lower concentrations and absolute amounts of TAG in egg yolk than hens fed the control diet $(P=0.07$ and $P=0.06$, respectively; Table 3 ). Concentrations and absolute amounts of cholesterol in egg yolk did not differ between these two groups of hens.

Hens fed the diet containing CLA had higher concentrations of TAG and cholesterol in liver $(P<0 \cdot 05)$ and tended to have higher concentration of cholesterol in plasma than control hens $(P=0.06$; Table 3$)$. Concentration of TAG in plasma was not altered in hens fed the diet containing CLA compared to control hens. Moreover, both concentration and absolute amount of TAG in egg yolks tended to be lower in hens fed the diet containing fish oil compared to control hens ( $P=0.07$ and $P=0.06$, respectively); concentration of cholesterol in egg yolk did not differ between those two groups of hens (Table 3). Hens fed the diet containing CLA tended to have higher concentrations of TAG and cholesterol in egg yolk than control hens $(P=0.06$ and $P=0.10$, respectively). Absolute amounts of TAG and cholesterol in egg yolk were higher in hens fed the diet containing CLA than in control hens $(P<0.05$, Table 3$)$. 


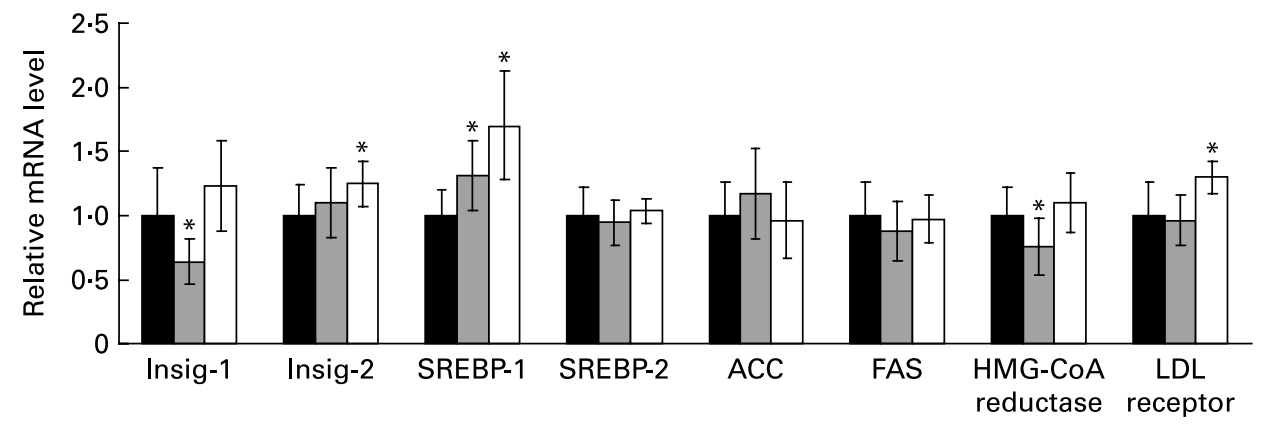

Fig. 2. Effect of feeding laying hens diets containing (30 g/kg) sunflower oil (control, $\square$ ), fish oil ( $\square$ ) or conjugated linoleic acids (CLA; $\square$ ) for $5 \mathrm{keeks}$ on the mRNA levels of insulin-induced gene (Insig)-1 and -2 , sterol regulatory element-binding protein (SREBP)-1 and -2, acetyl-CoA carboxylase (ACC), fatty acid synthase (FAS), 3-hydroxy-3-methylglutaryl-CoA (HMG-CoA) reductase and LDL receptor in the liver. Total RNA was extracted from the liver and relative mRNA levels of the genes were determined by RT-PCR analysis using $\beta$-actin mRNA level for normalisation. Values are means with standard deviation indicated by vertical bars for ten hens per group. Mean values were significantly different from control group: ${ }^{\star} P<0.05$.

\section{Discussion}

To our knowledge, this is the first study which investigated the effects of fish oil and CLA in laying hens on the expression of genes controlled by PPAR $\alpha$ and SREBP, transcription factors that control whole-body lipid homeostasis. Hens received diets containing sunflower oil, fish oil or CLA for 5 weeks. To study whether the dietary oils activated PPAR $\alpha$, we determined mRNA levels of classical PPAR $\alpha$ target genes, namely ACO, CPT-1A and the peroxisomal bifunctional enzyme. Feeding fish oil to laying hens caused a significant up-regulation of ACO and bifunctional enzyme compared to feeding sunflower oil which was used as a control fat. Although we did not perform a direct PPAR $\alpha$ activation assay, this finding suggests that $n-3$ PUFA present in fish oil were able to bind to and activate PPAR $\alpha$. It should be noted that, since the upregulation of these genes was relatively weak, being 45 and $50 \%$ for ACO and bifunctional enzyme, respectively, $n-3$ PUFA probably caused only a slight activation of PPAR $\alpha$ in the liver of hens. This is in contrast to rodents in which administration of fish oil causes a much stronger up-regulation of PPAR $\alpha$ target genes in the liver. For example, in the study

(A)

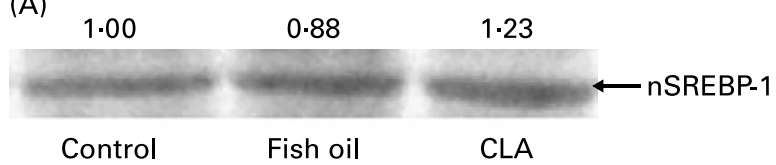

(B)

$\begin{array}{ccc}1.00 & 0.58 & 0.83 \\ \text { Control } & \text { Fish oil } & \text { CLA }\end{array}$ nSREBP-2

Fig. 3. Effect of feeding laying hens diets containing $(30 \mathrm{~g} / \mathrm{kg})$ sunflower oil (control), fish oil or conjugated linoleic acids (CLA) for 5 weeks on the concentration of nuclear sterol regulatory element-binding protein (SREBP)-1 (A) and SREBP-2 (B) in the liver. Liver nuclear extracts of five hens per group were pooled and $90 \mu \mathrm{g}$ of the samples were separated by $10 \%$ SDSPAGE and immunoblotted with anti-SREBP-1 and anti-SREBP-2 antibodies, respectively. Numbers indicate intensity of the SREBP-specific bands relative (about $68 \mathrm{kDa}$ ) to control $(=1.00)$ as obtained from densitometric analysis. of Nakatani et al. ${ }^{(19)}$, feeding a diet containing fish oil for one week increased mRNA level of ACO in the liver of mice four-fold.

The data of the present study, moreover, show that the CLA mixture administered to the hens, with cis-9, trans-11 and trans-10, cis-12 CLA as the main isomers, did not significantly up-regulate gene expression of PPAR $\alpha$ target genes although there were some numerical increases in mRNA levels of ACO and bifunctional enzyme. It is therefore concluded that dietary CLA does not activate PPAR $\alpha$, or at most to a very small extent, in the liver of laying hens under in vivo conditions. This is in contrast to studies in rat liver cells which demonstrated that both of these isomers are able to bind to and activate $\operatorname{PPAR} \alpha^{(15,16)}$. The disagreement between the present study and the rat liver cell study may be that rat liver cells have a very high gene expression of PPAR $\alpha$ in the liver, which is several-fold greater than in other species ${ }^{(35,36)}$.

In rodents, PPAR $\alpha$ activation leads to a reduction of liver and plasma TAG concentration ${ }^{(37)}$. The increased expression of genes involved in fatty acid $\beta$-oxidation is one of the mechanisms underlying the hypotriacylglycerolaemic effect upon PPAR $\alpha$ activation ${ }^{(5)}$. In laying hens, treatment with clofibrate also caused a strong reduction of liver and plasma TAG concentration which suggests that PPAR $\alpha$ activation may affect fatty acid and TAG metabolism in a similar way as in rodents ${ }^{(3)}$. Thus, it is likely that PPAR $\alpha$ activation contributed to the reduction of plasma TAG concentrations observed in hens fed the diet containing fish oil. It should be noted, however, that fish oil has several other effects on lipid metabolism such as inhibiting assembly of VLDL or stimulating the expression of PPAR cofactors ${ }^{(38,39)}$. These effects could also contribute to alterations in plasma lipid concentrations observed in hens fed fish oil.

In mammals, $n-3$ PUFA cause a down-regulation of SREBP-1 at the transcriptional level which in turn inhibits transcription of genes involved in hepatic de novo fatty acid synthesis such as FAS or $\mathrm{ACC}^{(40,41)}$. The present study shows that $n-3$ PUFA do not exert such an effect in the liver of laying hens. It is shown that mRNA level of SREBP-1 is even increased by fish oil in the liver of hens. It has been shown that gene expression and activation of SREBP-1c in the liver are triggered by activation of liver X-receptor, a receptor which is activated by oxysterols ${ }^{(42)}$. Studies in rats 
Table 3. Concentrations of TAG and total cholesterol in liver, plasma and egg yolks of laying hens fed diets containing $(30 \mathrm{~g} / \mathrm{kg})$ sunflower oil (control), fish oil or conjugated linoleic acids (CLA) for 5 weeks

(Mean values with standard deviations for ten hens per group)

\begin{tabular}{|c|c|c|c|c|c|c|}
\hline & \multicolumn{2}{|c|}{ Control } & \multicolumn{2}{|c|}{ Fish oil } & \multicolumn{2}{|c|}{ CLA } \\
\hline & Mean & SD & Mean & SD & Mean & SD \\
\hline \multicolumn{7}{|l|}{ TAG } \\
\hline Liver $(\mu \mathrm{mol} / \mathrm{g})$ & 43.9 & $10 \cdot 9$ & $36 \cdot 5$ & 8.7 & $62 \cdot 0^{*}$ & $20 \cdot 8$ \\
\hline Plasma (mmol/l) & $20 \cdot 0$ & $4 \cdot 1$ & $15 \cdot 3^{*}$ & 2.9 & $21 \cdot 8$ & 9.5 \\
\hline Egg yolk $(\mu \mathrm{mol} / \mathrm{g})$ & 125 & 26 & $106^{\star *}$ & 17 & $160^{\star *}$ & 50 \\
\hline Egg yolk (mmol/yolk) & $2 \cdot 29$ & 0.59 & $1.87^{\star \star}$ & 0.32 & $3 \cdot 36^{\star}$ & $1 \cdot 17$ \\
\hline \multicolumn{7}{|l|}{ Total cholesterol } \\
\hline Liver $(\mu \mathrm{mol} / \mathrm{g})$ & $7 \cdot 75$ & $1 \cdot 16$ & $7 \cdot 87$ & 1.54 & $10 \cdot 38^{*}$ & 1.62 \\
\hline Plasma (mmol/l) & $3 \cdot 62$ & 0.74 & $2 \cdot 79^{\star}$ & 0.62 & $4 \cdot 61^{*}$ & $1 \cdot 28$ \\
\hline Egg yolk $(\mu \mathrm{mol} / \mathrm{g})$ & $15 \cdot 9$ & $1 \cdot 8$ & $16 \cdot 2$ & $2 \cdot 2$ & $17 \cdot 2^{\star \star}$ & 1.5 \\
\hline Egg yolk ( $\mu \mathrm{mol} /$ yolk) & 288 & 26 & 286 & 39 & $360^{\star}$ & 49 \\
\hline
\end{tabular}

Mean values were significantly different from control group: ${ }^{\star} P<0.05,{ }^{\star \star} P<0.10$.

have shown that induction of oxidative stress, i.e. by administration of fish oil, enhances the formation of oxysterols in the liver ${ }^{(43)}$. Although the diet used in this study contained an adequate amount of vitamin $\mathrm{E}$, it is possible that administration of fish oil enhanced the formation of oxysterols which in turn caused a liver X-receptor-induced activation of SREBP-1 in the liver of the hens. Nevertheless, an elevated mRNA level of SREBP-1 in the liver of hens fed a diet containing fish oil did not result in increased concentration of nuclear SREBP-1 which was instead marginally decreased. Consistent with that, mRNA levels of SREBP-1 target genes ACC and FAS were also unchanged. These data suggest that fish oil did not inhibit lipogenesis in the liver of hens.

In addition to reduced plasma TAG concentration we found that the TAG concentration of egg yolks also tended to be decreased by fish oil feeding. TAG from the liver are secreted via VLDL into the blood, and they are taken up by oocyte receptors. Thus we suggest that, due to enhanced fatty acid oxidation, VLDL secretion from the liver and uptake by oocyte receptors was reduced leading to reduced TAG concentration in egg yolk.

For SREBP-2, no alteration in mRNA level was observed upon fish-oil feeding but the concentration of nuclear SREBP-2 in the liver was decreased. In agreement with that, mRNA level of the SREBP-2 target gene HMG-CoA reductase and that of Insig-1, whose transcription is also regulated by SREBP, was reduced in hens treated with fish oil. In agreement with reduced expression of HMG-CoA reductase, the key enzyme of cholesterol synthesis, cholesterol concentration in the plasma of hens fed fish oil was reduced. A similar reduction of plasma cholesterol concentration was also observed in another study by feeding fish oil to young chicks $^{(44)}$. In rats, it has been shown that activation of PPAR $\alpha$ causes an inhibition of the processing of the immature SREBP-2, leading to a reduced SREBP-2 activity in the liver which in turn causes a reduction of hepatic cholesterol synthesis and plasma cholesterol concentration ${ }^{(37,45)}$. Thus, the possibility exists that processing of SREBP-2 in hens fed fish oil was also inhibited by activation of PPAR $\alpha$.

The present study reveals that feeding CLA up-regulates LDL receptor in the liver of laying hens. This effect that could contribute to the increased cholesterol concentration in the liver observed in hens fed the diet containing CLA. A similar up-regulation of LDL receptor expression by trans-10, cis-12 CLA was also observed in HepG2 cells and was dependent on the up-regulation of SREBP-2 ${ }^{(23)}$. In hens fed CLA, level of SREBP-2 mRNA was unchanged and that of nuclear SREBP-2 was marginally decreased indicating that up-regulation of LDL receptor was probably not mediated by SREBP-2 in the liver of hens fed CLA. Consistent with almost unchanged concentration of nuclear SREBP-2, mRNA levels of SREBP-2 target genes HMG-CoA reductase and Insig-1 were also not altered. In mammals, LDL receptor expression is also regulated via specificity protein-1 and activator protein-1 binding sites and by liver X-receptor $\alpha^{(46-48)}$. Data on effects of dietary CLA on plasma and liver lipids in mammals are inconsistent revealing decreased, unchanged and increased cholesterol levels ${ }^{(49-52)}$. Taken together, the reasons for the increased liver and plasma cholesterol concentrations in hens fed CLA cannot be completely explained by the data of this study.

The present study shows that CLA, like fish oil, caused an up-regulation of SREBP-1 mRNA expression in the liver of hens. Nevertheless, the concentration of mature SREBP-1 protein in the nucleus was only marginally increased and the mRNA levels of both SREBP-1 target genes ACC and FAS remained unchanged. Thus, elevated mRNA levels of SREBP-1 did not result in increased nuclear concentration of the protein. This may be due to the increased expression of Insig-2. Dependent on cholesterol concentration, Insig retard the SREBP precursor proteins in the endoplasmic reticulum thereby preventing their proteolytic activation ${ }^{(24,25)}$. In mice, Insig-2a, the liver-specific transcript of Insig-2, is regulated by insulin and thus plays a special role in regulation of SREBP-1c maturation allowing fatty acid synthesis even at elevated cholesterol concentrations ${ }^{(53)}$. The finding that CLA increases hepatic TAG concentration agrees with recent studies in laying hens ${ }^{(54,55)}$. In these studies, even a low concentration of a mixture of CLA ( $5 \mathrm{~g} / \mathrm{kg}$ diet $)$ caused an increase of the number of lipid vacuoles in the liver of laying hens and an increased concentration of liver total lipids. Nevertheless, the reason for the increased hepatic TAG concentration in hens fed CLA remains unclear. Studies in mice demonstrated that trans-10, cis-12 CLA induces hyperinsulinaemia and fatty liver which may be caused by reduced leptin and adiponectin 
plasma concentrations and an up-regulation of PPAR $\gamma$, adipocyte lipid-binding protein, fatty acid transporter mRNA and

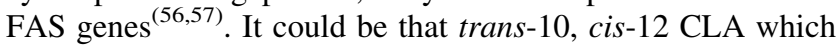
made up approximately $50 \%$ of total dietary CLA isomers exerted similar effects in the liver of hens.

Interestingly, we found also an increase in egg yolk weights and in yolk TAG and cholesterol concentrations in hens fed the diet containing CLA. Effects of CLA on egg yolk weight reported in literature are variable. In some studies dietary CLA lowered egg or yolk weights ${ }^{(58-60)}$ whereas in others CLA did not alter egg or yolk weights ${ }^{(61,62)}$. Results about the effects of CLA on egg yolk lipids are also variable ${ }^{(55,61,62)}$. In our study, both TAG and cholesterol concentrations in egg yolks were increased by dietary CLA. It is possible that the increased yolk weights and increased concentrations of TAG and cholesterol in egg yolk are linked to increased TAG concentrations in the liver and increased cholesterol concentrations in liver and plasma. It is possible that VLDL secretion from the liver and uptake into oocytes were increased in hens fed CLA which resulted in increased cholesterol and TAG transfer into egg yolk.

In conclusion, this study shows for the first time that fish oil causes a moderate up-regulation of PPAR $\alpha$ target genes in the liver of laying hens but had less effect on the concentration of nuclear SREBP-1 in the liver and its target genes involved in TAG synthesis. Possibly, up-regulation of PPAR $\alpha$ target genes contributed to reduced plasma TAG concentration observed in hens fed fish oil. It is also shown that the concentration of nuclear SREBP-2 and expression of HMG-CoA reductase is decreased by fish oil. This suggests that fish oil lowers hepatic cholesterol synthesis, an effect that might contribute to decreased plasma cholesterol concentration in these hens. It is furthermore shown that a mixture of CLA with cis-9, trans-11 and trans10, cis-12 CLA does not significantly up-regulate PPAR $\alpha$ target genes and has less effect on nuclear concentrations of SREBP-1 and SREBP-2 and their target genes. This suggests that CLA do not influence synthesis of TAG and cholesterol in the liver. Nevertheless, hens fed CLA had higher concentrations of TAG in liver and of cholesterol in liver and plasma and a higher concentration of TAG and cholesterol in egg yolks than control hens. The mechanisms underlying these effects have to be elucidated in further studies.

\section{Acknowledgements}

B. K. supervised gene expression analyses, participated in the interpretation of the results and prepared the manuscript; J. S. determined nuclear concentrations of SREBP; K. H. and H. K. planned and carried out the animal experiment; C. B. supervised the lipid analyses; G. S. participated in the design of the study, and interpretation of the results; K. E. conceived the study and its design, coordinated work, participated in the interpretation of the results, and helped to draft the manuscript. There was no specific funding for this study and there is not any potential conflict of interest.

\section{References}

1. Walzem RL, Hansen RJ, Williams DL \& Hamilton RL (1999) Estrogen induction of VLDL assembly in egg-laying hens. J Nutr 129, 467S-472S
2. Hermier D, Forgez P, Williams J \& Chapman MJ (1989) Alterations in plasma lipoproteins and apolipoproteins associated with estrogen-induced hyperlipidemia in the laying hen. Eur J Biochem 184, 109-118.

3. König B, Kluge H, Haase K, Brandsch C, Stangl GI \& Eder K (2007) Effects of clofibrate treatment in laying hens. Poult Sci 86, $1187-1195$.

4. Desvergne B \& Wahli W (1999) Peroxisome proliferator-activated receptors: nuclear control of metabolism. Endocr Rev 20, 649-688.

5. Mandard S, Müller M \& Kersten S (2004) Peroxisome proliferator-activated receptor alpha target genes. Cell Mol Life Sci 61, 393-416.

6. Staels B, Dallongeville J, Auwerx J, Schoonjans K, Leitersdorf E \& Fruchart JC (1998) Mechanism of action of fibrates on lipid and lipoprotein metabolism. Circulation 98, 2088-2093.

7. Horton JD, Goldstein JL \& Brown MS (2002) SREBPs: activators of the complete program of cholesterol and fatty acid synthesis in the liver. $J$ Clin Invest 109, 1125-1131.

8. Espenshade PJ, Li WP \& Yabe D (2002) Sterols block binding of COPII proteins to SCAP, thereby controlling SCAP sorting in ER. Proc Natl Acad Sci U S A 99, 11694-11699.

9. Goldstein JL, Rawson RB \& Brown MS (2002) Mutant mammalian cells as tools to delineate the sterol regulatory element-binding protein pathway for feedback regulation of lipid synthesis. Arch Biochem Biophys 397, 139-148.

10. Diot C \& Douaire M (1999) Characterization of a cDNA sequence encoding the peroxisome proliferator activated receptor alpha in the chicken. Poult Sci 78, 1198-1202.

11. Gondret F, Ferre P \& Dugail I (2001) ADD-1/SREBP-1 is a major determinant of tissue differential lipogenic capacity in mammalian and avian species. J Lipid Res 42, 106-113.

12. Assaf S, Hazard D, Pitel F, Morisson M, Alizadeh M, Gondret F, Diot C, Vignal A, Douaire M \& Lagarrigue S (2003) Cloning of cDNA encoding the nuclear form of chicken sterol response element binding protein-2 (SREBP-2), chromosomal localization, and tissue expression of chicken SREBP-1 and -2 genes. Poult Sci 82, 54-61.

13. Meng H, Li H, Zhao JG \& Gu ZL (2005) Differential expression of peroxisome proliferator-activated receptors alpha and gamma gene in various chicken tissues. Domest Anim Endocrinol 28, $105-110$

14. Matsuyama H, Sato K, Nakamura Y, Suzuki K \& Akiba Y (2005) Modulation of regulatory factors involved in cholesterol metabolism in response to feeding of pravastatin- or cholesterolsupplemented diet in chickens. Biochim Biophys Acta 1734, $136-142$.

15. Moya-Camarena SY, Vanden Heuvel JP \& Belury MA (1999) Conjugated linoleic acid activates peroxisome proliferator-activated receptor alpha and beta subtypes but does not induce hepatic peroxisome proliferation in Sprague-Dawley rats. Biochim Biophys Acta 1436, 331-342.

16. Moya-Camarena SY, Vanden Heuvel JP, Blanchard SG, Leesnitzer LA \& Belury MA (1999) Conjugated linoleic acid is a potent naturally occurring ligand and activator of PPARalpha. J Lipid Res 40, 1426-1433.

17. Clarke SD (2001) Polyunsaturated fatty acid regulation of gene transcription: a molecular mechanism to improve the metabolic syndrome. J Nutr 131, 1129-1132.

18. Kim HJ, Takahashi M \& Ezaki O (1999) Fish oil feeding decreases mature sterol regulatory element-binding protein 1 (SREBP-1) by down-regulation of SREBP-1c mRNA in mouse liver. A possible mechanism for down-regulation of lipogenic enzyme mRNAs. J Biol Chem 274, 25892-25898.

19. Nakatani T, Katsumata A, Miura S, Kamei Y \& Ezaki O (2005) Effects of fish oil feeding and fasting on LXRalpha/RXRalpha 
binding to LXRE in the SREBP-1c promoter in mouse liver. Biochim Biophys Acta 1736, 77-86.

20. Le Jossic-Corcos C, Gonthier C, Zaghini I, Logette E, Shechter I \& Bournot P (2005) Hepatic farnesyl diphosphate synthase expression is suppressed by polyunsaturated fatty acids. Biochem J 385, 787-794.

21. Ringseis R, Saal D, Muller A, Steinhart H \& Eder K (2004) Dietary conjugated linoleic acids lower the TAG concentration in the milk of lactating rats and impair the growth and increase the mortality of their suckling pups. J Nutr 134, 3327-3334.

22. Takahashi Y, Kushiro M, Shinohara K \& Ide T (2003) Activity and mRNA levels of enzymes involved in hepatic fatty acid synthesis and oxidation in mice fed conjugated linoleic acid. Biochim Biophys Acta 1631, 265-273.

23. Ringseis R, König B, Leuner B, Schubert S, Nass N, Stangl G \& Eder K (2006) LDL receptor gene transcription is selectively induced by t10c12-CLA but not by c9t11-CLA in the human hepatoma cell line HepG2. Biochim Biophys Acta 1761, $1235-1243$.

24. Yang T, Espenshade PJ, Wright ME, Yabe D, Gong Y, Aebersold R, Goldstein JL \& Brown MS (2002) Crucial step in cholesterol homeostasis: sterols promote binding of SCAP to INSIG-1, a membrane protein that facilitates retention of SREBPs in ER. Cell 110, 489-500.

25. Yabe D, Brown MS \& Goldstein JL (2002) Insig-2, a second endoplasmic reticulum protein that binds SCAP and blocks export of sterol regulatory element-binding proteins. Proc Natl Acad Sci U S A 99, 12753-12758.

26. Naumann C \& Bassler R (1976) Chemical Analysis of Feedstuffs. Method Book, vol. III. Darmstadt, Germany: VDLUFA verlag.

27. Gesellschaft für Ernährungsphysiologie (GfE) (1999) Energie- und Nährstoffbedarf landwirtschaftlicher Nutztiere, Nr.7. Empfehlungen zur Energie- und Nährstoffversorgung der Legehennen und Masthühner (Requirement of Energy and Nutrients of Farm Animals, no. 7. Recommendations for Energy and nutrient Supply of Laying Hens and Broilers). Frankfurt, Germany: DLG-Verlag.

28. Hara A \& Radin NS (1978) Lipid extraction of tissues with a low toxicity solvent. Anal Biochem 90, 420-426.

29. De Hoff JL, Davidson JH \& Kritchevsky V (1978) An enzymatic assay for determining free and total cholesterol in tissues. Clin Chem 24, 433-435.

30. Brandsch C, Ringseis R \& Eder K (2002) High dietary iron concentrations enhance the formation of cholesterol oxidation products in the liver of adult rats fed salmon oil with minimal effects on antioxidant status. $J$ Nutr 132, 2263-2269.

31. Sehat N, Rickert R, Mossoba MM, et al. (1999) Improved separation of conjugated fatty acid methyl esters by silver ion-highperformance liquid chromatography. Lipids 34, 407-413.

32. König B \& Eder K (2006) Differential action of 13-HPODE on PPAR $\alpha$ downstream genes in rat Fao and human HepG2 hepatoma cell lines. J Nutr Biochem 17, 410-418.

33. Pfaffl MW (2001) A new mathematical model for relative quantification in real-time RT-PCR. Nucleic Acids Res 29, e45.

34. Woo CWH, Siow YL, Pierce GN, Choy PC, Minuk GY \& Mymin D (2005) Hyperhomocysteinemia induces hepatic cholesterol biosynthesis and lipid accumulation via activation of transcription factors. Am J Physiol Endocrinol Metab 288, E1002-E1010.

35. Tugwood JD, Holden PR, James NH, Prince RA \& Roberts RA (1998) A peroxisome proliferator-activated receptor-alpha $(\mathrm{PPAR} \alpha)$ cDNA cloned from guinea-pig liver encodes a protein with similar properties to the mouse PPARalpha: implications for species differences in responses to peroxisome proliferators. Arch Toxicol 72, 169-177.

36. Holden PR \& Tugwood JD (1999) Peroxisome proliferator-activated receptor $\alpha$ : role in rodent liver cancer and species differences. J Mol Endocrinol 22, 1-8.
37. König B, Koch A, Spielmann J, Hilgenfeld C, Stangl GI \& Eder K (2007) Activation of PPAR $\alpha$ lowers synthesis and concentration of cholesterol by reduction of nuclear SREBP-2. Biochem Pharmacol 73, 574-585.

38. Botham KM, Zheng X, Napolitano M, Avella M, Cavallari C, Rivabene R \& Bravo E (2003) The effects of dietary n-3 polyunsaturated fatty acids delivered in chylomicron remnants on the transcription of genes regulating synthesis and secretion of very-low-density lipoprotein by the liver: modulation by cellular oxidative state. Exp Biol Med (Maywood) 228, 143-151.

39. Bassaganya-Riera J \& Hontecillas R (2006) CLA and n-3 PUFA differentially modulate clinical activity and colonic PPARresponsive gene expression in a pig model of experimental IBD. Clin Nutr 25, 454-465.

40. Clarke SD, Armstrong MK \& Jump DB (1990) Dietary polyunsaturated fats uniquely suppress rat liver fatty acid synthase and S14 mRNA content. J Nutr 120, 225-231.

41. Geelen MJ, Schoots WJ, Bijleveld C \& Beynen AC (1995) Dietary medium-chain fatty acids raise and $(n-3)$ polyunsaturated fatty acids lower hepatic TAG synthesis in rats. J Nutr 125, 2449-2456.

42. Geyeregger R, Zeyda M \& Stulnig TM (2006) Liver X receptors in cardiovascular and metabolic disease. Cell Mol Life Sci 63, $524-539$.

43. Ringseis R \& Eder K (2002) Insufficient dietary vitamin E increases the concentration of 7ß-hydroxycholesterol in tissues of rats fed salmon oil. J Nutr 132, 3732-3735.

44. Castillo M, Amalik F, Linares A \& Garcia-Peregrin E (2000) Fish oil reduces cholesterol and arachidonic acid levels in plasma and lipoproteins from hypercholesterolemic chicks. Mol Cell Biochem 210, 121-130.

45. Patel DD, Knight BL, Wiggins D, Humphreys SM \& Gibbons GF (2001) Disturbances in the normal regulation of SREBPsensitive genes in PPAR alpha-deficient mice. J Lipid Res $\mathbf{4 2}$, 328-337.

46. Fu Y, Huang Y, Bandyopadhyay S, Virella G \& Lopes-Virella MF (2003) LDL immune complexes stimulate LDL receptor expression in U937 histiocytes via extracellular signal-regulated kinase and AP-1. J Lipid Res 44, 1315-1321.

47. Sekar N \& Veldhuis JD (2004) Involvement of Sp1 and SREBP1a in transcriptional activation of the LDL receptor gene by insulin and LH in cultured porcine granulosa-luteal cells. Am J Physiol Endocrinol Metab 287, E128-E135.

48. Ishimoto K, Tachibana K, Sumitomo M, et al. (2006) Identification of human low-density lipoprotein receptor as a novel target gene regulated by liver $\mathrm{X}$ receptor alpha. FEBS Lett 580, 4929-4933.

49. Kelley DS, Bartolini GL, Warren JM, Simon VA, Mackey BE \& Erickson KL (2004) Contrasting effects of t10,c12- and c9,t11conjugated linoleic acid isomers on the fatty acid profiles of mouse liver lipids. Lipids 39, 135-141.

50. Tricon S, Burdge GC, Kew S, Banerjee T, Russell JJ, Jones EL, Grimble RF, Williams CM, Yaqoob P \& Calder PC (2004) Opposing effects of cis-9,trans-11 and trans-10,cis-12 conjugated linoleic acid on blood lipids in healthy humans. Am J Clin Nutr 80, 614-620.

51. Navarro V, Miranda J, Churruca I, Fernandez-Quintela A, Rodriguez VM \& Portillo MP (2006) Effects of trans-10,cis12 conjugated linoleic acid on body fat and serum lipids in young and adult hamsters. $J$ Physiol Biochem 62, 81-87.

52. Porsgaard T, Xu X \& Mu H (2006) The form of dietary conjugated linoleic acid does not influence plasma and liver TAG concentrations in Syrian golden hamsters. J Nutr 136, 2201-2206.

53. Yabe D, Komuro R, Liang G, Goldstein JL \& Brown MS (2003) Liver-specific mRNA for Insig-2 down-regulated by insulin: implications for fatty acid synthesis. Proc Natl Acad Sci U S A 100, 3155-3160. 
54. Cherian G \& Goeger MP (2004) Hepatic lipid characteristics and histopathology of laying hens fed CLA or $n$-3 fatty acids. Lipids 39, 31-36.

55. Cherian G, Holsonbake TB, Goeger MP \& Bildfell R (2002) Dietary CLA alters yolk and tissue FA composition and hepatic histopathology of laying hens. Lipids 37, 751-757.

56. Clement L, Poirier H, Niot I, Bocher V, Guerre-Millo M, Krief S, Staels B \& Besnard P (2002) Dietary trans-10, cis-12 conjugated linoleic acid induces hyperinsulinemia and fatty liver in the mouse. J Lipid Res 43, 1400-1409.

57. Poirier H, Rouault C, Clement L, Niot I, Monnot MC, GuerreMillo M \& Besnard P (2005) Hyperinsulinaemia triggered by dietary conjugated linoleic acid is associated with a decrease in leptin and adiponectin plasma levels and pancreatic beta cell hyperplasia in the mouse. Diabetologia 48, 1059-1065.

58. Raes K, Huyghebaert G, De Smet S, Nollet L, Arnouts S \& Demeyer D (2002) The deposition of conjugated linoleic acids in eggs of laying hens fed diets varying in fat level and fatty acid profile. J Nutr 132, 182-189.

59. Suksombat W, Samitayotin S \& Lounglawan P (2006) Effects of conjugated linoleic acid supplementation in layer diet on fatty acid compositions of egg yolk and layer performances. Poult Sci 85, 1603-1609.

60. Szymczyk B \& Pisulewski PM (2003) Effects of dietary conjugated linoleic acid on fatty acid composition and cholesterol content of hen egg yolks. Br J Nutr 90, 93-99.

61. Schäfer K, Männer K, Sagredos A, Eder K \& Simon O (2001) Incorporation of dietary linoleic and conjugated linoleic acids and related effects on eggs of laying hens. Lipids 36, $1217-1222$.

62. Ahn DU, Sell JL, Jo C, Chamruspollert M \& Jeffrey M (1999) Effect of dietary conjugated linoleic acid on the quality characteristics of chicken eggs during refrigerated storage. Poult Sci 78, 922-928. 